\title{
Effect of L-arginine additive on the growth and physical properties of Potassium Dihydrogen Phosphate single crystals
}

\author{
E.I.Kostenyukova ${ }^{1}$, A.V.Uklein ${ }^{2}$, V.V.Multian ${ }^{2}$, I.M.Pritula ${ }^{1}$, \\ O.N.Bezkrovnaya ${ }^{1}$, A.G.Doroshenko ${ }^{1}$, S.V.Khimchenko ${ }^{3}$, \\ A.G.Fedorov ${ }^{3}$, A.N.Levchenko ${ }^{4}$, A.I.Starikov ${ }^{4}$, V.Ya.Gayvoronsky $^{2}$ \\ ${ }^{1}$ Institute for Single Crystals, STC "Institute for Single Crystals", \\ National Academy of Sciences of Ukraine, \\ 60 Nauky Ave., 61072 Kharkiv, Ukraine \\ ${ }^{2}$ Institute of Physics, National Academy of Sciences of Ukraine, \\ 46 Nauky Ave., 03028 Kyiv, Ukraine \\ ${ }^{3}$ Division of Functional Materials Chemistry, SSI "Institute for Single \\ Crystals", National Academy of Sciences of Ukraine, \\ 60 Nauky Ave., 61072 Kharkiv, Ukraine \\ ${ }^{4}$ V.Karazin Kharkiv National University, \\ 4 Svobody Sq., 61022 Kharkiv, Ukraine
}

\section{Received January 12, 2018}

\begin{abstract}
Potassium dihydrogen phosphate (KDP) single crystals doped with L-arginine (L-arg) amino acid were grown from aqueous solutions onto a point seed using the temperature reduction method. The incorporation of L-arg molecules into the crystal was verified by means of ninhydrin reaction. Undoped and L-arginine doped KDP crystals were characterized by XRD method and structure perfection of the doped crystals was shown to correspond to the one of pure KDP. It was established that incorporation of L-arg molecules into KDP crystal had an effect on the formation of additional bonds in the crystal structure, that manifested itself in the thermal properties of the doped crystals. Investigation of $\varepsilon_{\perp} / \varepsilon_{\|}$value which characterizes the dielectric permittivity anisotropy showed that it was minimal at 0.5-1.0 wt. \% L-arg concentrations. In this case, the introduced L-arg seems to lead to creation of additional hydrogen bonds and disappearance of proton vacancies bound up with aliovalent impurities. Since the crystals contain different impurity defects, L-arg molecules are oriented in the lattice in a different way, depending on the type of the defects, and diminish the anisotropy. The present study testifies that the attenuation of the values of DC conductivity, dielectric permittivity and loss tangent at L-arg concentrations of $1 \mathrm{wt} . \%$ is probably related to the content decrease of the proton vacancies and the impurity-proton vacancy complexes dipoles, formed due to incorporation of the impurity ions into the crystal. The incorporation of L-arg molecules into the crystalline matrix results in an order of magnitude enhancement of the refractive nonlinear optical (NLO) response efficiency and its sign turn to self-focusing effect versus the self-defocusing obtained in the nominally pure KDP crystal. Similar kind of the NLO response efficiency rise in the $\mathrm{KDP}$ single crystals doped with $\mathrm{TiO}_{2}$ nanoparticles. The phenomenon can produce the enhancement of the optical harmonics generation efficiency due to the laser radiation localization and improvement of phase matching conditions realization.
\end{abstract}

Keywords: KDP crystals, L-arginine, DC conductivity, self-action effects, nonlinear refraction. 
Монокристаллы дигидрофосфата калия (KDP), допированные аминокислотой L-аргинин (L-arg), выращены из водных растворов на точечной затравке методом снижения температуры. Вхождение молекул L-arg в кристалл подтверждено с помощью нингидриновой реакции. Чистые кристаллы KDP и допированные L-arg охарактеризованы методом рентгендифрактометрии. Показано, что структурное совершенство допированных кристаллов соответствует чистому KDP. Установлено, что вхождение молекул L-arg в кристалл KDP сопровождается формированием дополнительных водородных связей в решетке кристалла, проявляющееся в изменении термических свойств допированного кристалла. Показано, что величина $\varepsilon_{\perp} / \varepsilon_{\mid}$, характеризующая анизотропию диэлектрической проницаемости, имеет минимальное значение при концентрациях L-arg 0,5-1,0 масс.\%. При этом вхождение молекул L-arg приводит к образованию дополнительных водородных связей в решетке и исчезновению протонных вакансий, связанных с присутствием алиовалентных примесей. Поскольку в кристаллах существуют различные примесные дефекты, то молекулы L-arg в зависимости от вида дефекта ориентируются в решётке различным образом, уменьшая анизотропию. Уменьшение значения величин проводимости, диэлектрической проницаемости, тангенса угла потерь при концентрациях L-arg 1 масс.\%, вероятно, связано с уменьшением количества протонных вакансий и диполей, включающих примесный дефект и протонную вакансию, образующихся в результате вхождения в кристалл примесных ионов. Вхождение молекул L-arg в кристаллическую матрицу приводит к увеличению на порядок эффективности рефрактивного нелинейно-оптического отклика и изменению его знака, самодефокусировка лазерного излучения, наблюдаемая для чистого $\mathrm{KDP}$, изменяется на самофокусировку. Аналогичное увеличение эффективности нелинейно-оптического отклика наблюдалось в кристаллах $\mathrm{KDP}$, допированных наночастицами $\mathrm{TiO}_{2}$. Это явление может обеспечить повышение эффективности генерации оптических гармоник за счет локализации лазерного излучения и улучшения реализации условий фазового синхронизма.

Вплив L-аргініну на оптичні властивості, досконалість кристалічної структури та лазерну міцність кристалів KDP. E.І.Костенюкова, А.В.Уклё̈н, В.В.Мультян, I.М.Притула, О.М.Безкровна, А.Г.Дорошенко, С.В.Хімченко, О.Г.Федоров, О.М.Левченко, О.І.Старіков, В.Я.Гайворонський.

Монокристали дигідрофосфату калію (KDP), що доповані амінокислотою L-аргінін (L-arg), вирощено з водних розчинів на точковій затравці методом зниження температури. Входження молекул L-arg у кристал підтверджено за допомогою нінгідринової реакції. Чисті та доповані L-arg кристали KDP охарактеризовані методом рентгендіфрактометрії. Показано, що структурна досконалість допованих кристалів відповідає чистому KDP. Встановлено, що входження молекул L-arg у кристал KDP супроводжується формуванням додаткових водневих зв'язків у гратці кристала, що проявляється у зміні термічних властивостей допованного кристала. Показано, що величина $\varepsilon_{\perp} / \varepsilon_{\|}$, яка характеризує анізотропію діелектричної проникності, має мінімальне значення при концентраціях L-arg 0,5-1,0 мас.\%. При цьому входження молекул L-arg призводить до утворення додаткових водневих зв'язків у гратці і зникнення протонних вакансій, що пов'язані з присутністю аліовалентних домішок. Оскільки у кристалах існують різні домішкові дефекти, то молекули L-arg в залежності від виду дефекту орієнтуються у гратці різним чином, зменшуючи анізотропію. Зменшення значення величин провідності, діелектричної проникності та тангенсу кута втрат при концентраціях L-arg 1 мас.\%, ймовірно, пов'язано зі зменшенням кількості протонних вакансій і диполей, що включають домішковий дефект та протонну вакансію, які утворюються у результаті входження у кристал домішкових іонів. Входження молекул L-arg у кристалічну матрицю призводить до збільшення на порядок ефективності рефрактивного нелінійно-оптичного відгуку і зміни його знаку, самодефокусування лазерного випромінювання, що спостерігається для чистого KDP, змінюється на самофокусування. Аналогічне збільшення ефективності нелінійно-оптичного відгуку спостерігалося у кристалах $\mathrm{KDP}$, які доповані наночастинками $\mathrm{TiO}_{2}$. Це явище може забезпечити підвищення ефективності генерації оптичних гармонік за рахунок локалізації лазерного випромінювання і поліпшення реалізації умов фазового синхронізму.

\section{Introduction}

Potassium dihydrogen phosphate (KDP, $\left.\mathrm{KH}_{2} \mathrm{PO}_{4}\right)$ single crystals attract much attention due to their wide applications in frequency converters, electro-optic switching and modulators [1]. KDP-family crystals pos- sess high structure perfection, mechanical strength, wide range of spectral transparency, as well as relatively high values of laser damage threshold. Moreover, the growth technology makes it possible to obtain KDP crystals with well-developed growth sectors containing practically no defects. Nevertheless, 
relatively low value of quadratic susceptibility is one of the main functional restrictions for the use of KDP crystals.

To increase the efficiency of second harmonic generation in these crystals, numerous studies have been performed to find out possible methods for raising the efficiency of laser radiation conversion by modifying the structure of the well-known nonlinear optical single crystals of KDP-family [2-6]. As shown by Xue et al. [6], in KDP family crystals hydrogen bonds essentially contribute to nonlinear optical phenomena such as quadratic electrooptical effect and generation of higher harmonics. It has been shown that the nonlinear optical (NLO) characteristics of KDP can be controlled due to increase of the number of the hydrogen bonds in the crystals and optimization of their spatial arrangement [7]. As found in [8], the incorporation of a number of amino acids into the structure of KDP group crystals raises the efficiency of second harmonic generation (SHG). The amino acid molecules have high polarizability due to the processes of internal charge transfer between the donor $\left(\mathrm{COO}^{-}\right)$and acceptor $\left(\mathrm{NH}_{2}{ }^{+}\right)$groups $[9,10]$. The effect of the doping with L-arg amino acid on the SHG efficiency of KDP is reported by Parikh K.D. et al. [9]. The efficiency of SHG in KDP:L-arg, grown with the addition of 0.3 wt. $\%$ and $0.4 \mathrm{wt}$. $\%$ of L-arg increases by a factor of 1.33 and 1.74, respectively, in comparison with that of pure KDP. When studying the effect of L-arg on the electrical properties of KDP single crystals, Meena et al. [11] show that the electrical parameters of the doped KDP, viz. DC and AC conductivity, dielectric constant and loss tangent diminish with the increase of L-arg concentration due to the reduction of L-defects mainly caused by creation of additional hydrogen bonds by the L-arg which impedes the motion of protons.

In that regard, the goal of the present work was the growth and characterization of a series of KDP crystals with different content of L-arginine amino acid. There was investigated the impact of L-arg on growth, structure perfection, thermal and electrical properties of KDP crystals. The contribution of the L-arg additive to the nonlinear optical (NLO) response of the KDP:L-arg samples was studied by the photoinduced absorption and refractive index variations versus the peak intensity of the picosecond laser pulses at $1064 \mathrm{~nm}$.

\section{Experimental}

The initial $\mathrm{KH}_{2} \mathrm{PO}_{4}$ salt was synthesized from the high-purity reagents $\mathrm{H}_{3} \mathrm{PO}_{4}$ and $\mathrm{KOH}$, the concentration of the impurities (Al, Cr, Mg, Mn, Fe, etc.) in $\mathrm{KH}_{2} \mathrm{PO}_{4}$ salt did not exceed $10^{-5}$ wt. \%. L-arg amino acid (Aldrich) was used in the capacity of dopant. Nominally pure KDP single crystals and the ones with incorporated L-arg were grown by the temperature reduction method [12] onto $5 \times 5 \times 10 \mathrm{~mm}^{3}$ point seed. The initial solutions $(\mathrm{pH} 4.0 \pm 0.1)$ were prepared at a saturation temperature of $50.2-51.3^{\circ} \mathrm{C}$ in accordance with the solubility curve. The concentration of L-arg in the mother liquor was $0 ; 1.0 ; 1.4 ; 2.2$ and 3.8 wt. $\%$ with respect to KDP salt. The solutions were filtered through fluoroplastic filters with $0.05 \mathrm{~mm}$ pore diameter and then overheated during 24 hours at $T=70^{\circ} \mathrm{C}$. The relative solution supersaturation $\sigma$ was $~ 0.25-1 \%$. To provide dynamic crystal growth conditions, the solution contained in the crystallizer was mixed at a rate of $70 \mathrm{rpm}$. The average rates of the growth of the doped crystals along the growth directions were $V_{z}$ $=2.0-1.6 \mathrm{~mm} /$ day and $V_{x, y}=1.3-0.8 \mathrm{~mm}$ /day with the rise of the dopant concentration up to $3.8 \mathrm{wt}$. \% . All the grown crystals had well-developed growth sectors $\{100\}$ and $\{101\}$. The dimensions $(a \times b \times c)$ of the grown KDP:L-arg crystals with L-arg contained in the mother liquor were the following: $61 \times 50 \times 90 \mathrm{~mm}^{3}(1.0$ wt. $\%$ of L-arg $)$, $46 \times 44 \times 52 \mathrm{~mm}^{3} \quad(1.4$ wt. $\%$ of L-arg), $35 \times 31 \times 51 \mathrm{~mm}^{3} \quad(2.2$ wt. $\%$ of L-arg), $42 \times 36 \times 87 \mathrm{~mm}^{3}$ (3.8 wt. \% of L-arg).

Determination of L-arg concentrations in the crystals and solutions was realized by means of ninhydrin reaction based on the formation of a colored product during the interaction between the amino acid and ninhydrin at heating in alkaline medium. In the capacity of reagents there were used potassium dihydrogen phosphate (ultra-high pure); 1 M sodium hydroxide solution (chemically pure), $0.2 \%$ ninhydrin solution (chemically pure), $0.1 \%$ L-arg solution (chemically pure), deionized water $(18 \mathrm{M} \Omega \cdot \mathrm{cm})$. The measurements were realized on a SF-2000 BIO spectrophotometer. The content of L-arg in the sample was determined by means of the gauge curve or the method of additions. Thereat, a weight of the analyzed KDP sample was ground and dissolved in 10-25 $\mathrm{ml}$ of water, supplemented sequentially with sodium hydroxide 
and ninhydrine solutions, and then heated up to $90^{\circ} \mathrm{C}$ during $30 \mathrm{~min}$.

Differential thermal (DT) and thermogravimetric (TG) analyses of pure KDP and KDP:L-arg crystals were realized on a MOM Q-1500D derivatograph (Hungary) within $20-500^{\circ} \mathrm{C}$ temperature range. The heating rate was $2.5 \mathrm{deg} / \mathrm{min}$; as a standard, there was used aluminum alpha-oxide.

The lattice parameters of KDP samples were measured with a general-purpose X-ray diffractometer using $\mathrm{CuK} \alpha_{1}$ radiation and graphite monochromator in a primary beam. To minimize errors, there was used the Bond data acquisition method [13]. The rocking curves (RC) were obtained on a double-crystal spectrometer at $\mathrm{CuK} \alpha_{1}$ radiation with silicon monochromator adjusted to the (400) reflection. The used arrangement allows us to pick out well-resolved $\mathrm{K}_{1}$ line of the X-ray spectrum. RC's in $(n,-m)$ scheme of the spectrometer geometry were obtained for the (008) KDP reflection. The measured values of Full Width at Half Maximum (FWHM) may be roughly estimated by comparison with the calculated ones obtained in accordance with [14]. $W$, is:

$$
W=\sqrt{\omega_{M}^{2}+\Delta \theta_{\lambda}^{2}+\omega_{S}^{2}} .
$$

Here, $\omega_{M}$ and $\omega_{S}$ are the diffraction line widths for the monochromator and the sample, correspondingly; $\Delta \theta_{\lambda}$, the angular spread due to the asymmetry of the monochromator and the crystal sample disposition. The calculated value equal to 94 arc sec confirms a good structure perfection of KDP crystals.

The electrical measurements were performed on $2.0 \times 2.0 \times 0.3 \mathrm{~cm}^{3}$ crystal plates cut out of the pyramidal $(\{101\}, P)$ and prismatic $(\{100\}, P r)$ growth sectors. The value of resistance $R$ was determined using a teraohmmeter E6-13A according to the three-electrode scheme. The voltage applied to the samples was $100 \mathrm{~V}$. The electrodes were made from conducting rubber. The diameter of the measuring electrode $d_{1}$ and the inner diameter of the guard ring $d_{2}$ were equal to 1.4 and $1.6 \mathrm{~cm}$, respectively. The gap between the measuring and guard electrodes was $0.1 \mathrm{~cm}$. The dependence of the conductivity on the concentration of L-arg was measured at $T=18-19^{\circ} \mathrm{C}$. The error defined by the accuracy of the measurement of the samples dimensions and the error of the device did not exceed $~ 4-6 \%$.
The resistivity $\rho$ and specific conductivity $\sigma$ of the crystals were calculated from the formulas:

$$
\rho \equiv 1 / \sigma=\pi\left(d_{1}+d_{2}\right)^{2} \cdot R / 16
$$

The relative dielectric constant $\varepsilon_{r}$ and the loss tangent $(\tan \delta)$ were measured at a frequency of $1 \mathrm{kHz}$ and $T=18-19^{\circ} \mathrm{C}$ using a digital capacitance meter E8-4. For $\varepsilon_{r}$ determination graphite electrodes with a diameter of $1.5 \mathrm{~cm}$ were placed onto the opposite sides of the samples to measure the capacity of the obtained capacitor. The value of dielectric permittivity was calculated from relation (2) for capacitor:

$$
\varepsilon_{r}=\frac{C \cdot d}{\varepsilon_{0} \cdot A},
$$

where $C$ is the capacity of the capacitor containing the sample; $\varepsilon_{0}$, the dielectric permittivity of vacuum; $A$ and $d$, the area and thickness of the sample, respectively. The accuracy of $\varepsilon_{r}$ measurement was $\pm 3 \%$. The error of $\tan \delta$ determination did not exceed $\pm 16 \%$.

The absorptive and refractive NLO responses were studied by the photoinduced total and on-axis transmittance variations due to the self-action of the picosecond laser pulses at wavelength $1064 \mathrm{~nm}$ $(1.17 \mathrm{eV})$. The measurements were performed according to the approach described in [15]. For the excitation we utilized the radiation of the mode-locked $\mathrm{Nd}^{3+}$ :YAG laser with pulsewidth 42 ps (FWHM) and repetition rate $15 \mathrm{~Hz}$. The samples were positioned at the input aperture $(1 \mathrm{~cm}$ diameter) of the photodiode in order to avoid impact of the scattering extinction losses. We have thoroughly checked the reversibility of the photoinduced transmittancies variations with rise/reduction of the input laser radiation intensity $I$. Fitting the experimental data of the on-axis and total transmittancies versus the peak laser intensity $I$ according to the route described in [15] provides estimation of the photoinduced refractive index $(\Delta n)$ and absorption coefficient $(\Delta \alpha)$ variations magnitudes that are proportional to the real/imaginary part of the cubic NLO susceptibility $\Delta n \sim \operatorname{Re}\left(\chi^{(3)}\right) I$ and $\Delta \alpha \sim \operatorname{Im}\left(\chi^{(3)}\right) I$. 

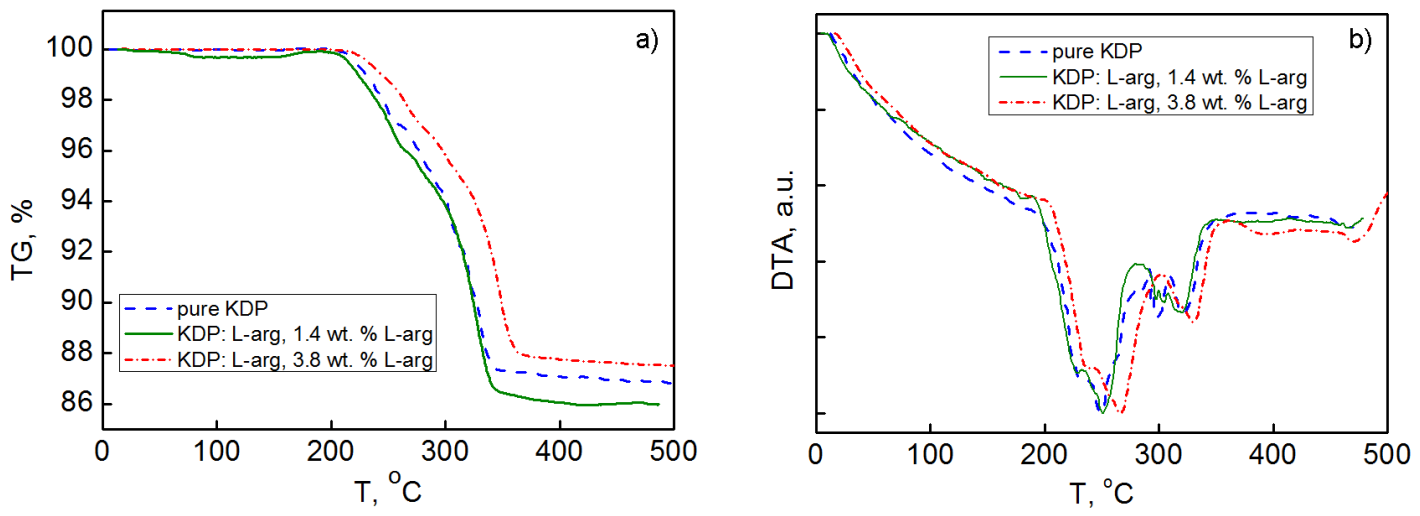

Fig. 1. TGA (a) and DTA (b) spectra of pure KDP and KDP:L-arg crystals.

Table 1. Concentration of L-arg amino acid in as-grown KDP crystal

\begin{tabular}{||c|c|c|c|c||}
\hline $\begin{array}{c}\text { Concentration of } \\
\text { L-arg in mother } \\
\text { liquor, wt. \% }\end{array}$ & Growth sector & $\begin{array}{c}\text { Concentration of L- } \\
\text { arg in KDP } \\
\text { crystal, wt. \% }\end{array}$ & $\begin{array}{c}\text { Effective } \\
\text { segregation } \\
\text { coefficient of L-arg } \\
\text { in KDP crystal }\end{array}$ & $*{ }^{*}, C_{S}$ \\
\hline 1.0 & $\{101\}$ & 0.04 & 0.04 & 12 \\
1.4 & $\{100\}$ & 0.06 & 0.06 & 8.2 \\
& $\{101\}$ & 0.1 & 0.07 & 4.5 \\
& $\{100\}$ & 0.1 & 0.07 & 3.0 \\
& $\{101\}$ & 0.05 & 0.02 & 13 \\
\hline
\end{tabular}

${ }^{*} C_{S}$ - experimental error, \%.

\section{Results and discussion}

KDP:L-arg crystals grown at 1.0-2.2 wt. \% concentration of L-arg in the mother liquor were found to possess high optical transparency in the visible spectral region. The increase of L-arg concentration in the solution up to 3.8 wt. \% gave rise to striation in the sector $\{101\}$, probably due to capture of the solution. Chemical analysis of the KDP:L-arg samples confirmed incorporation of L-arg molecules into KDP crystals.

As shown earlier [16], L-arg molecules are effectively incorporated into the growth sectors $\{101\}$ and $\{100\}$ of KDP crystal. Adsorption of L-arg molecules by the growing faces $\{100\}$ is caused by the fact that the carboxyl and amino groups of the dopant are able to form hydrogen bonds with the phosphate groups which terminate the growing faces $\{100\}$. In its turn, electrostatic interaction of the negatively charged groups $\mathrm{COO}^{-}$of L-arg molecules with the positively charged face $\{101\}$ leads to adsorption of the dopant in the growth sector
\{101\}. As seen from Table 1, the coefficient of incorporation of L-arg into KDP crystal varies from 0.01 to 0.07 . Thereat, the content of L-arg in the crystal increases as the concentration of the dopant in the mother liquor rises up to $\sim 1.4$ wt. $\%$. With further growth of the content of L-arg in the solution in the range of 2.2-3.8 wt. \% its concentration in the crystal diminishes approximately by 3-4 times. This seems to be due to blocking of the growing crystal faces by the dopant molecules and to the corresponding decrease of the growth rate of KDP:L-arg crystal.

Incorporation of L-arg molecules into KDP crystal had an effect on the formation of additional bonds in the crystal structure, that manifested itself in the thermal properties of the doped crystals. As seen from Fig. 1a, the TG-thermogram of pure KDP practically does not show a mass loss in the range of $30-200^{\circ} \mathrm{C}$, but then this loss becomes noticeable. At the same time, for KDP:L-arg crystal with the increase of L-arg concentration from 1.4 to 3.8 wt. $\%$ the 

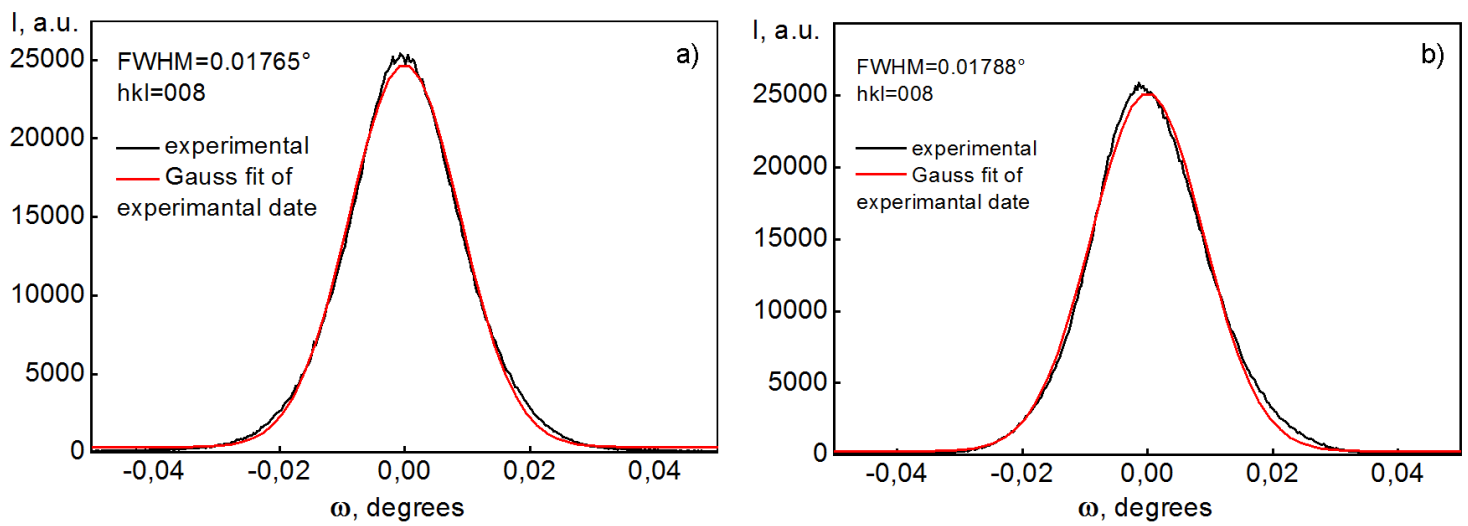

Fig. 2. Rocking curves of pure KDP (a) and KDP:L-arg (b) crystals, cut of from $\{101\}$ growth sectors.

mass loss is observed at temperatures $200^{\circ} \mathrm{C}, 215^{\circ} \mathrm{C}$ and $230^{\circ} \mathrm{C}$ that testifies to the rise of the decomposition temperature for KDP:L-arg crystals. The process of mass loss is fast at temperatures up to $380^{\circ} \mathrm{C}$ and slow at temperatures up to $500^{\circ} \mathrm{C}$. The mass loss in $200-380^{\circ} \mathrm{C}$ temperature range is caused by KDP and L-arg decomposition. The observed rise of the decomposition temperature with the increase of the concentration of L-arg points to the fact that incorporation of L-arg into KDP crystals raises their thermal stability.

Fig. 1b presents the DTA curves of pure and L-arg doped KDP crystal. For the pure crystal there is observed a doubled endothermal peak with maxima at $230^{\circ} \mathrm{C}$ and $248^{\circ} \mathrm{C}$. With the growth of L-arg concentration from 1.4 to 3.8 wt. \% these maxima are registered at $237^{\circ} \mathrm{C}$ and $266^{\circ} \mathrm{C}$. The shift of the maxima testifies to the rise of the thermal stability of the doped KDP crystals. It should be noted that, as reported in a number of papers, the phase stability of KDP crystals grown in the presence of amino acids was observed either to increase or to diminish. The rise of the phase stability of the crystals was registered at their doping with L-Glutamic acid, L-Histidine, L-Valine [17], as well as with L-arginine, L-histidine and glicine [18]. At the same time, introduction of glicine [19], L-alanine [20], L-Arginine and L-Alanine [21] into KDP crystals was found to somewhat reduce their thermal stability, obviously due to the increase of the dopant content in the crystal, that also leads to worsening of the optical properties of these crystals.

To study the influence of L-arg molecules on the structure perfection of the matrix, there were measured the rocking curves of KDP and KDP:L-arg crystals. The study performed on KDP and KDP:L-arg (1.4 wt. \% of L-arg) ( $\mathrm{P}$ and $\mathrm{Pr}$ growth sectors) shows that the structure perfection of the doped crystals corresponds to the one of pure KDP (Table 2). The rocking curves of pure KDP and KDP:L-arg crystals (P) are presented in Fig. 2. The rocking curves for the samples cut out from the sector $\mathrm{Pr}$ for the pure and doped crystals are similar to those shown in the figure.

As we have found earlier [12], the change of the crystal lattice periods shows the rise of the crystal lattice parameters by the values $\Delta a=2.42 \cdot 10^{-4} \AA$ $(\{101\})$ and $\Delta a=2.45 \cdot 10^{-4} \AA \quad(\{100\})$ for KDP:L-arg samples. Thereat, the value of the parameter $c$ in KDP:L-arg changes with respect to the one of KDP crystal: $\Delta c=$ $-9.5 \cdot 10^{-5} \AA \quad(\{101\})$ and $\Delta c=-8.0 \cdot 10^{-5} \AA$ $(\{100\})$. It is known that KDP crystal has a tetramolecular unit cell with $a=7.452 \AA$ and $c=6.974 \AA$ [22].

Measurements of DC conductivity in KDP samples cut out from different parts of the crystals along the axes $a$ and $c$ testify to an essential influence of the doping addition and its concentration on the specific conductivity of the crystals. Depending on the concentration of L-arg, the conductivity of some crystals may either rise by an

Table 2. FWHM values measured in pure KDP and KDP:L-arg crystals

\begin{tabular}{|c|c|}
\hline Samples & $\begin{array}{c}\text { FWHM, } \\
\text { arcsec }\end{array}$ \\
\hline Pure KDP, $\{101\}, z$ & 63.54 \\
Pure KDP, $\{100\}, z$ & 64.58 \\
KDP:L-arg, 1.4 wt. \% L-arg, $\{101\}, z$ & 64.37 \\
KDP:L-arg, 1.4 wt. \% L-arg, $\{100\}, z$ & 66.71 \\
\hline
\end{tabular}




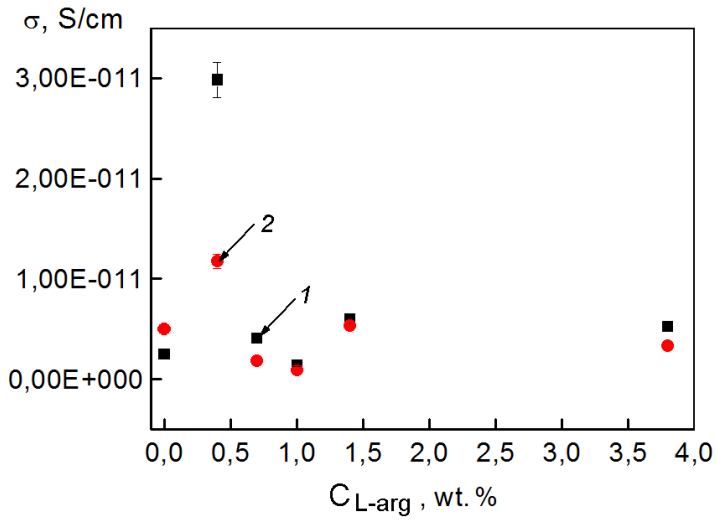

Fig. 3. Dependences of conductivity of KDP crystals (along $a$ - (1) and $c$-directions (2)) on L-arg concentration for the pyramidal sector.

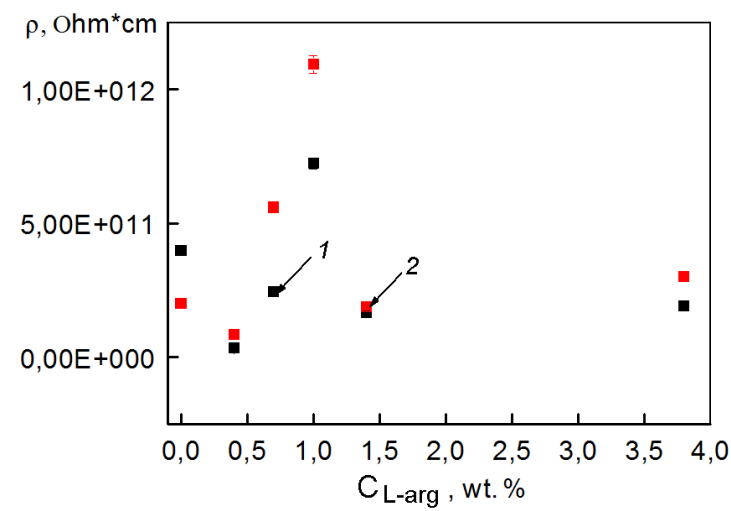

Fig. 4. Dependences of resistivity $(\rho)$ of KDP (along $a$ - (1) and $c$-directions (2)) crystals on L-arg content for the pyramidal sector.

order of magnitude or diminish by 5 times. Such changes are defined rather by the part of the crystal used for manufacture of the sample than by the direction in the crystal along which the measurements have been realized. The common feature in the behavior of the concentration dependences for all the samples is the rise of the conductivity at low L-arg concentrations (0.4-0.7 wt. \%) followed by its essential decrease to the values lower than those for the undoped samples at concentrations up to $1.0 \mathrm{wt}$. $\%$, and subsequent increase with the growth of the dopant concentration.

Typical dependences of conductivity for KDP crystals on the concentration of L-arg in the solution are shown in Fig. 3. The values of $\sigma$ differ depending on the part of the crys-

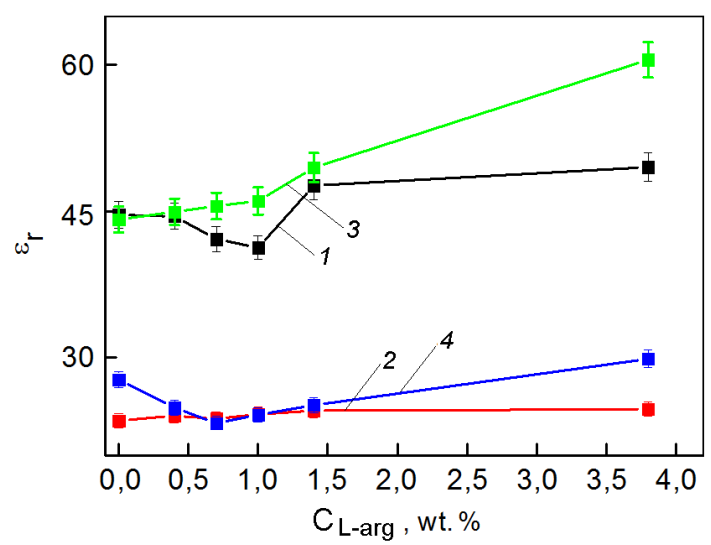

Fig. 5. Dependences of the dielectric permittivity of KDP crystals on L-arg content for the pyramidal $(1,2)$ and prismatic $(3,4)$ sectors of crystal growth along $a-(1,3)$ and $c$-directions $(2,4)$.

tal used for the making of the investigated samples (Table 3). With the increase of the dopant concentration both $\sigma_{\perp}$ and $\sigma_{\|}$at first rise and reach their minimum and afterwards start to grow again. The corresponding changes in the resistivity are shown in Fig. 4. As is seen, at low concentrations of L-arg it diminishes, then rises, reaches the values exceeding the resistance of the undoped crystals, then diminishes again. Non-monotonic dependences are observed at the measurements realized both along $\rho_{\|}$and perpendicular $\rho_{\perp}$ to the crystal axis $c$. The resistivity maximum corresponds to the interval of L-arg concentrations $\left(C_{\mathrm{Arg}}\right) 0.7<C_{\mathrm{Arg}}<1.4$ wt. \% .

The change of relative dielectric permittivity depending on the concentration of L-arg is presented in Fig. 5. As is seen, introduction of L-arg into KDP increases the value of the longitudinal $\varepsilon_{c}=\varepsilon_{\|}=\varepsilon_{33}$ and transversal $\varepsilon_{a}=\varepsilon_{\perp}=\varepsilon_{11}=\varepsilon_{22}$ components of the tensor of relative dielectric permittivity especially pronounced for the prismatic sector (growth sector effect). Thereat, within a certain interval of L-arg concentrations, there is observed the dielectric permittivity minimum, or diminution of the rate of its rise with the increase of L-arg concentration. It should be noted that this occurs within the same interval $0.7-1.4$ wt. $\%$ of L-arg con-

Table 3. Conductivity $\sigma$ for pyramidal and prismatic growth sectors

\begin{tabular}{||c|c|c|c|}
\hline \multicolumn{2}{|c|}{ Pyramidal sector $\{101\}$} & \multicolumn{2}{c|}{ Prismatic sector $\{100\}$} \\
\hline$\sigma_{\perp}=8.6 \cdot 10^{-13} \div 2.9 \cdot 10^{-11}$ & $\sigma_{\|}=1.2 \cdot 10^{-12} \div 1.7 \cdot 10^{-11}$ & $\sigma_{\perp}=1.7 \cdot 10-13 \div 2.0 \cdot 10^{-11}$ & $\sigma_{\|}=1.1 \cdot 10^{-13} \div 5.3 \cdot 10^{-11}$ \\
\hline
\end{tabular}



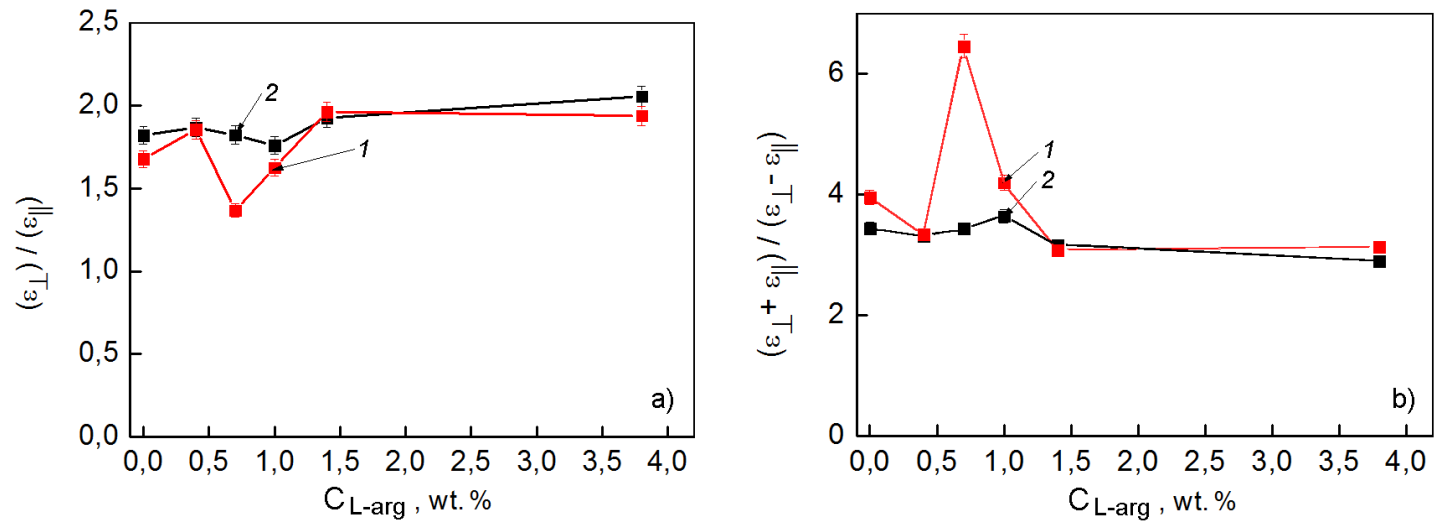

Fig. 6. Effect of L-arg additive on dielectric permittivity anisotropy: $k_{1}=\varepsilon / \varepsilon_{\|}$(Fig. 6a) and $k_{2}=$ $\left(\varepsilon_{\perp}+\varepsilon_{\|}\right) /\left(\varepsilon_{\perp}-\varepsilon_{\|}\right)$(Fig. 6b) for crystal growth sectors: $1-\{100\}, 2-\{101\}$.

centrations where the resistivity $\rho$ also increases.

As seen from Fig. 6 , the values of $k_{1}=\varepsilon_{1} \varepsilon_{\|}$ (Fig. 6a) and $k_{2}=\left(\varepsilon_{\perp}+\varepsilon_{\|} / \varepsilon_{\perp}-\varepsilon_{\|} \quad\right.$ (Fig. 6b) which characterize dielectric permittivity anisotropy which depends on the concentration of L-arg. The dependences $k_{1}$ and $k_{2}$ for the pyramidal and prismatic growth sectors have different behavior, thereat for the prismatic sector the concentration-related changes of the said parameters are most pronounced (crystal growth sector effect).

The behavior of the value of the loss tangent $(\tan \delta)$ depending on the concentration of L-arg is analogous to the concentration dependence of conductivity. With the rise of the L-arg concentration the value of $\tan \delta$ at first increases and then diminishes to the values characteristic of those for the undoped crystals, and afterwards it grows again. A typical dependence is shown in Fig. 7. As is seen, the minimum of the loss tangent corresponds to 1.0 wt. \% concentration of the doping addition.

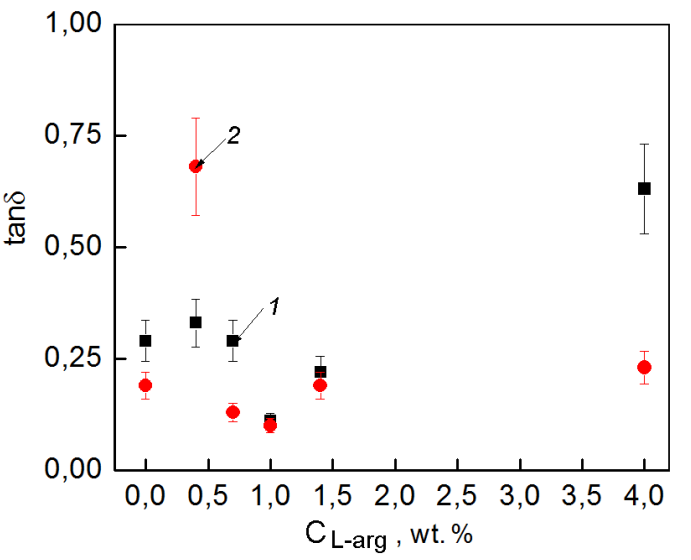

Fig. 7. Loss tangent for the perpendicular directions $\tan \delta_{\perp}(1)$ and parallel direction $\tan \delta_{\|}$

(2) of the pyramidal sector of KDP:L-arg.

Nowadays there are known several mechanisms of conductivity in KDP crystals, see [23-26]. However, since in the present study the measurements have been performed at room temperature, there must be considered the mechanism connected with the presence of aliovalent impu-

Table 4. Comparison of the refractive $\operatorname{Re}\left(\chi^{(3)}\right)$ and absorptive $\operatorname{Im}\left(\chi^{(3)}\right)$ cubic nonlinear-optical responses efficiencies and the quality parameter FOM for the KDP:L-arg and the nominally pure KDP single crystals in the peak intensity range $I<30 \mathrm{MW} / \mathrm{cm}^{2} . L-$ sample thickness, $I_{t}$ and $I_{a}$ - the saturation peak intensity and on-axis transmittance extremum position, see Fig. 8

\begin{tabular}{|c|c|c|c|c|c|c||}
\hline \hline Sample & $\begin{array}{c}\text { Growth } \\
\text { Sector }\end{array}$ & $L, \mathrm{~mm}$ & $\begin{array}{c}I_{t} / I_{a}, \\
\mathrm{MW} / \mathrm{cm}^{2}\end{array}$ & $\operatorname{Re}\left(\chi^{(3)}\right), 10^{-9} \mathrm{esu}$ & $\operatorname{Im}\left(\chi^{(3)}\right), 10^{-12}$ esu & FOM \\
\hline \multirow{2}{*}{ KDP } & $\mathrm{P}$ & 0.49 & $27 / 18$ & -2.9 & 1.2 & 64.0 \\
& $\mathrm{Pr}$ & 0.82 & $47 / 54$ & -0.7 & 0.3 & 61.8 \\
KDP:L-arg & $\mathrm{P}$ & 0.54 & $57 / 42$ & 12.0 & 1.9 & 167.4 \\
& $\mathrm{Pr}$ & 0.54 & $63 / 23$ & 11.0 & 2.0 & 145.8 \\
\hline
\end{tabular}



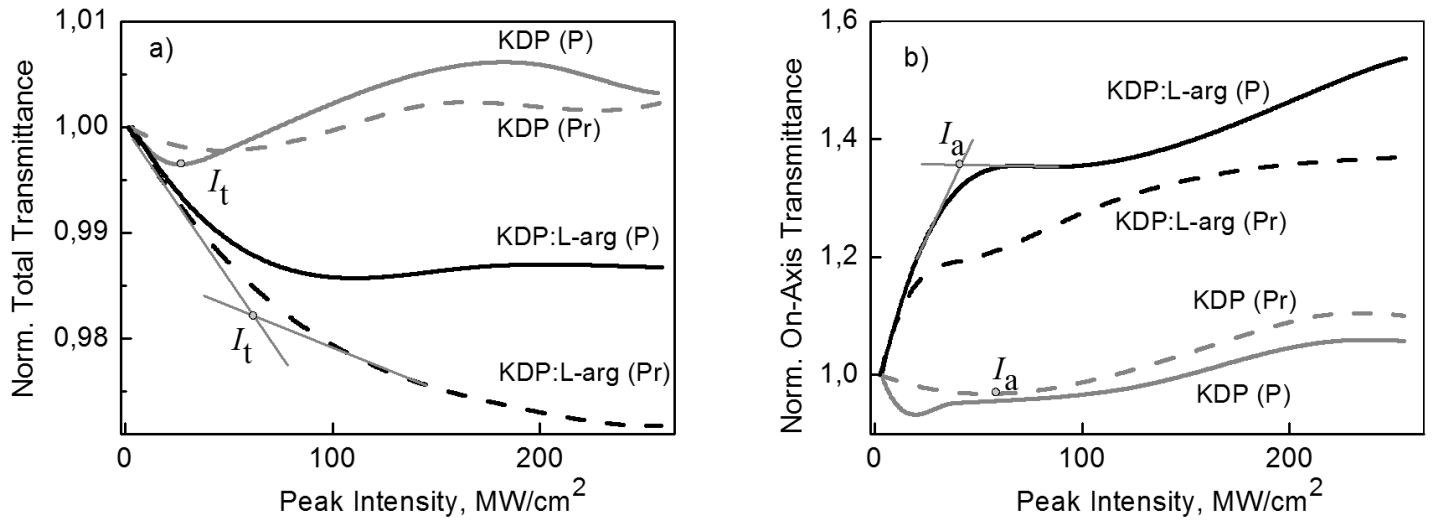

Fig. 8. Photoinduced variations of the total (a) and on-axis (b) transmittances of the KDP and the KDP:L-arg single crystals cut from pyramidal (P) and prismatic (Pr) growth sectors under pulsed laser excitation at $1064 \mathrm{~nm}$.

rities which give rise to L-defects (proton vacancies) in the crystals. This mechanism [11, 27-29] dominates at temperatures close to room temperature

In the presence of aliovalent impurities [28] charge compensation is usually realized by creation of proton vacancies. If the local environment of an impurity ion contains charge-compensating centers, then there are formed dipolar complexes earlier considered in [28] and other works while studying ionic thermo-currents in KDP containing chromium ions. The dipolar complexes consisting of impurities and proton vacancies influence the conductivity and dielectric characteristics of the crystals.

Irradiation of KDP crystals with ionizing radiation is known to give rise to modification of the hydrogen bonds which changes their length [30]. As shown while studying irradiation with high-energy protons, the shift of protons changes the conductivity and the dielectric properties [31].

Similarly to irradiation, doping of the crystals with organic additives also results in modification of their hydrogen bonds. As assumed in [11], L-arg molecules substitute cations in KDP crystals and occupy some interstices. The increase of the parameter $a(b)$ during introduction of L-arg into the lattice of these crystals observed in [16] testifies to modification of the hydrogen bonds. Therefore, it should be expected that the introduced L-arg will raise the conductivity, dielectric permittivity, loss tangent and diminish the activation energy of conductivity, just as it takes place in the case of modification of the hydrogen bonds at irradiation of the crystals by high-energy protons [30, 31]. Indeed, as we have found in the present study, for certain intervals of L-arg concentrations the values of conductivity, dielectric permittivity and the loss tangent rise with the L-arg content.

On the whole, the dependences of the considered values, in contrast to those obtained in [11], are non-monotonic (Fig. 3). At (0.7-1.4) wt. \% content of L-arg, the values of conductivity, dielectric permittivity, the loss tangent at first decrease, as consistent with the results obtained in [11], and then rise. In [11] the decrease of the considered values depending on the concentration of L-arg is explained by the fact that L-arg creates additional hydrogen bonds resulting in diminution of the concentration of L-defects. As known from EPR studies [3], undoped KDP crystals conventionally contain impurities of chromium, iron and other chemical elements. As noted above, some of these elements, e.g. chromium ions, influence the conductivity and dielectric characteristics of the crystals. Therefore, the decrease of the values of DC conductivity, dielectric permittivity, loss tangent at L-arg concentrations of $\sim 1$ wt. $\%$ is probably connected with the diminution of the quantity of proton vacancies and impurity-proton vacancy dipoles, formed due to incorporation of the impurity ions into the crystal.

Note that the increase of the value of dielectric permittivity at L-arg concentrations higher than 1 wt. \% (Fig. 5), is more pronounced for the $\operatorname{Pr}$ sector. The influence of L-arg on the dielectric permittivity in the $\mathrm{Pr}$ sector is more essential than the one in the $P$ sector. Therefore, L-arg incorporation into the crystal due to the carboxyl and amino groups is obviously predominating. In this case L-arg creates hydrogen bonds with the face (100). 
Investigation of $\varepsilon_{\perp} / \varepsilon_{\|}$value which charac-

terizes the dielectric permittivity anisotropy shows that it is minimal at $0.5-1.0 \mathrm{wt} \%$ L-arg concentrations. In this case, the introduced L-arg seems to lead to creation of additional hydrogen vacancies and disappearance of proton vacancies bound up with aliovalent impurities. Since the crystals contain different impurity defects, L-arg molecules are oriented in the lattice in a different way, depending on the type of the defects, and diminish the anisotropy. It is to be noted that the most essential anisotropy decrease takes place in the prismatic sector where, according to the data of [3], the quantity of impurity chromium and iron ions exceeds the one in the pyramidal sector.

The NLO properties of KDP and KDP:Larg single crystals were studied within the self-action of picosecond laser pulses at $1064 \mathrm{~nm}$. The photoinduced variations of the total and on-axis transmittances versus the peak intensity for the samples are presented in Fig. 8(a, b), correspondingly. It was shown that, in general, for the nominally pure crystals from $\mathrm{P}$ and $\mathrm{Pr}$ growth sectors the total transmittance variations do not exceed $0.5 \%$. For the initial peak intensity range both samples demonstrate slight photodarkening effect that is more pronounced for the one from $P$ growth sector. For the definite laser intensity $I_{t}$ the effect saturates (see Table 4) and turns to photobleaching. The observed higher $I_{t}$ magnitudes for the crystal from Pr growth sector can be explained by its higher thickness. The incorporation of L-arginine dopant results in significant enhancement of the photodarkening efficiency and higher $I_{t}$. For composite crystals $I_{t}$ was determined as tangents intersection point (see Fig 8a) that can be treated as a switching threshold from the initial effective response to the more saturated one.

We readout the refractive NLO response of the crystals providing the studies of the on-axis transmittance dependences versus the peak laser intensity. It was shown that even for both nominally pure samples the magnitudes of the photoinduced on-axis transmittance variations are significantly higher versus the absorptive ones. The nominally pure matrices demonstrate the self-defocusing effect that saturates at peak intensity $I_{a}$ (see Table 4). The L-arg dopant admixture results in one order of magnitude enhancement of the refractive NLO response and its sign turn to self-focusing effect that is more pronounced $\sim 50 \%$ for the KDP:L-arg crystal from $\mathrm{P}$ growth sector versus the $\sim 30 \%$ for the one from $\mathrm{Pr}$ growth sector. The effect saturation occurs at less peak intensity $I_{a}$ in comparison to the $I_{t}$ observed for the total transmittance dependences. It indicates the resonant origin of the studied processes in the crystals.

From the obtained total and on-axis transmittance dependences we calculated the imaginary $\operatorname{Im}\left(\chi^{(3)}\right)$ and real $\operatorname{Re}\left(\chi^{(3)}\right)$ parts of the cubic NLO susceptibility (see Table 4) according to the route described in [32] for initial peak intensity range $I<30 \mathrm{MW} / \mathrm{cm}^{2}$. It was show the L-arg dopant admixture results in significant enhancement of the absorptive and refractive NLO responses:

$\left|\operatorname{Re}\left(\chi^{(3)}\right)_{\mathrm{KDP}: \mathrm{L}-\arg }\right| \sim 4.1 \cdot\left|\operatorname{Re}\left(\chi^{(3)}\right)_{\mathrm{KDP}}\right|$ and $\left|\operatorname{Im}\left(\chi^{(3)}\right)_{\mathrm{KDP}: \mathrm{L}-\mathrm{arg}}\right| \sim$ 1.6.| $\operatorname{Im}\left(\chi^{(3)}\right)_{\mathrm{KDP}} \mid$ for $\mathrm{P}$ growth sector; $\left|\operatorname{Re}\left(\chi^{(3)}\right)_{\mathrm{KDP}: \mathrm{L}-\arg }\right|$ 15.7.| $\operatorname{Re}\left(\chi^{(3)}\right)_{\mathrm{KDP}} \mid$ and $\left|\operatorname{Im}\left(\chi^{(3)}\right)_{\mathrm{KDP}: \mathrm{L}-\arg }\right|$ 6.7.| $\operatorname{Im}\left(\chi^{(3)}\right)_{\mathrm{KDP}} \mid$ for $\operatorname{Pr}$ growth sector. The effect of efficient $\operatorname{Re}\left(\chi^{(3)}\right)$ rise and sign turn to self-focusing in comparison to the nominally pure KDP matrix is similar to the one observed in nanocomposites KDP with $\mathrm{TiO}_{2}$ nanoparticles $\left(\mathrm{KDP}: \mathrm{TiO}_{2}\right)$ [33, 34]. For the others ranges the observed NLO response enhancement is less due to the saturation of the aforementioned effects. The exception is the KDP:L-arg crystal from $\mathrm{P}$ growth sector for which $\left|\operatorname{Re}\left(\chi^{(3)}\right)_{\mathrm{KDP}: \mathrm{L}-\mathrm{arg}}\right| \sim 14.5 \cdot\left|\operatorname{Re}\left(\chi^{(3)}\right)_{\mathrm{KDP}}\right|$ in the range $40-50 \mathrm{MW} / \mathrm{cm}^{2}$.

For the initial range we calculated the conventional optical quality parameter - a figure of merit FOM $=\Delta n /(\lambda \delta \alpha)$, see Table 4 . The parameter reflects the gain in photoinduced refractive index versus the resonant absorption losses at the corresponding wavelength. It was shown that for the L-arginine doped KDP crystals the FOM magnitudes are about 2.5 times higher. It means that KDP:L-arg are promising nonlinear optical material for the laser and photonics applications due to the obtained high FOMs magnitudes.

It is known that the doping of the KDP crystals with complex organic molecules like L-arginine and L-valine results in SHG efficiency enhancement up to 30-70 \% that proportionally rises with the concentration of the organic compounds in the KDP [8]. The SHG efficiency enhancement up to $30 \%$ in the KDP with 2 wt. \% of carbamide was shown in [35]. The effect was determined by the additional deformation of $\left(\mathrm{PO}_{4}\right)^{3-}$ tetrahedron due to the hydrogen bonds formation between the amino group 
of carbamide and dihydrophosphate group of the crystalline matrix. In recent studies it was demonstrated that organic compounds (carbamide, xelenole orange) result in significant enhancement of $\left(\mathrm{PO}_{4}\right)^{3-}$ phosphate groups oscillations anharmonism of the KDP crystal and consequently in efficient rise of nonlinear electrooptical coefficient $d_{36}$ that determines high efficiency of quadric NLO response $\operatorname{Re}\left(\chi^{(2)}\right)$ [12].

The observed efficient self-focusing effect due to the L-arg incorporation is similar to the one observed for $\mathrm{KDP}: \mathrm{TiO}_{2}$ nanocomposites [33, 34]. It was shown that incorporation of metal oxide nanoparticles into the crystalline KDP matrix under definite excitation condition leads to the giant enhancement of the cubic NLO response $\operatorname{Re}\left(\chi^{(3)}\right)$. The effect results in intrinsic selffocusing of the pump laser beam that determines concentration of the laser radiation within an enhancement of the optical harmonics generation processes efficiency. Thus the KDP:L-arg crystal is promising medium for the laser frequency conversion due to the manifestation of both quadratic (direct impact) and degenerate cubic refractive (indirect impact through the self-focusing effect) responses enhancement.

\section{Conclusions}

The nominally pure KDP single crystals and those doped with L-arginine amino acid were grown. Determination of L-arg concentrations in the crystals by means of ninhydrin reaction indicated that the L-arg molecules have been embedded into the lattice of the KDP crystals. It was shown that the dopant incorporation produced an effect on the formation of additional bonds in the crystal structure that manifested in the thermal properties of the doped crystals. For the nominally pure crystal it was observed a doubled endothermal peak with maxima at $230^{\circ} \mathrm{C}$ and $248^{\circ} \mathrm{C}$. With the growth of L-arg concentration from 1.4 to 3.8 wt. \% these maxima are registered at $237^{\circ} \mathrm{C}$ and $266^{\circ} \mathrm{C}$. The shift of the maxima testifies to the rise of the thermal stability of the L-arg doped KDP crystals. The lattice parameters of KDP samples were measured by High Resolution XRD method. It was found that the change of the crystal lattice periods showed the rise of the crystal lattice parameters by the values $\Delta a=2.42 \cdot 10^{-4} \AA$ $(\{101\})$ and $\Delta a=2.45 \cdot 10^{-4} \AA$ ( $\left.\{100\}\right)$ for KDP:L-arg samples. The XRD study performed on the KDP and the KDP:L-arg
(1.4 wt. \% of L-arg) for different growth sectors showed that the structure perfection of the doped crystals corresponded to the one of the nominally pure KDP.

The present study indicates that the main feature in the character of the concentration dependences of DC-conductivity for all KDP:L-arg samples is the rise of the conductivity at low L-arg concentrations (0.4-0.7 wt. \%). At higher concentrations up to $1.0 \mathrm{wt}$. \% it was observed the essential reduction of the conductivity to the values less than those for the undoped crystals and its subsequent rise with further increase of L-arg content. The concentration dependences of the loss tangent and dielectric permittivity in KDP:L-arg crystals is similar to the DC-conductivity. Therefore, the attenuation of the DC-conductivity, dielectric permittivity, loss tangent magnitudes at L-arg concentrations of $~ 1$ wt. $\%$ is probably related to the content decrease of the proton vacancies and the impurity-proton vacancy complexes dipoles, being formed due to the incorporation of the impurity ions into the crystal.

The analysis of the picosecond laser pulses self-action effects at wavelength $1064 \mathrm{~nm}$ showed that the L-arg dopant admixture results in the self-focusing effect manifestation versus the self-defocusing one observed for the nominally pure KDP matrix. The efficiency of the refractive NLO response $\operatorname{Re}\left(\chi^{(3)}\right) \sim 10^{-8}$ esu is one order of magnitude higher for the KDP:L-arg single crystals. The effect is more pronounced in the plate cut from the $\mathrm{P}$ growth sector. We have the similar kind of the NLO response efficiency rise in the KDP single crystals doped with $\mathrm{TiO}_{2}$ nanoparticles [33, 34]. The observed efficient self-focusing effect can provide laser electric field concentration with consequent enhancement of the SHG yield.

Acknowledgments. The authors V.Ya.Gayvoronsky, A.V.Uklein, and V.V.Multian acknowledge partial support of this work by NAS of Ukraine Grant V-189.

\section{References}

1. D.Eimerl, Ferroelectrics, 72, 95 (1987).

2. B.Kahr, S.-H.Jang, J.A.Subromony, M.P.Kelly et al., Adv. Mater., 8, 941 (1996).

3. V.G.Grachev, I.A.Vrable, G.I.Malovichko et al., J.Appl.Phys., 112, 014315 (2012).

4. A.V.Kosinova, M.I.Kolybaeva, O.N.Bezkrovnaya et al., Cryst.Res.Technol., 49, 965 (2014).

5. I.M.Pritula, A.V.Kosinova, D.A.Vorontsov et al., J. Cryst. Growth, 355, 26 (2012). 
6. D.Xue, S.Zhang, Chem.Phys.Lett., 301, 449 (1999).

7. F.Zhang, K.Li, H.Ratajczak et al., J.Molec. Structure., 976, 69 (2010).

8. P.Kumaresan, S.Moorthy Babu, P.M.Anbarasan, Opt. Mater., 30, 1361 (2007).

9. K.D.Parikh, D.J.Dave, B.B.Parekh et al., Bull. Mater.Sci., 30, 105 (2007).

10. S.Gunasekaran, S.Ponnusamy, R.Rajasekaran, Indian J.Phys., 78, 553 (2004).

11. M.Meena, C.K.Mahadevan, Cryst.Res.Technol., 43, 166 (2008).

12. I.M.Pritula, E.I.Kostenyukova, O.N.Bezkrovnaya et al., Opt. Mater., 57, 217 (2016).

13. W.L.Bond, Acta Cryst., 13, 814 (1960).

14. A.H.Compton, S.K.Allison, The Interpretation of X-ray Spectra, in: X-Rays in Theory and Experiment, D.Van Nostrand, 2nd Ed.; New York (1967).

15. I.M.Pritula, A.V.Kosinova, O.N.Bezkrovnaya et al., Opt. Mater., 35, 2429 (2013).

16. E.I.Kostenyukova, O.N.Bezkrovnaya, M.I.Kolybaeva et al., Functional Materials, 23, 27 (2016).

17. P.Kumaresan, S.Moorthy Babu, P.M.Anbarasan, J.Opt.Adv.Mater., 9, 2780 (2007).

18. B.S.Kumar, K.R.Babu, Ind.J.Pure Appl. Phys., 46, 123 (2008).

19. U.Pisipaty, S.Sankar, R.Jayavel, Chem. Pharm.Sci., 1, 56 (2014).

20. K.D.Parikh, D.J.Dave, B.B.Parekh et al, Cryst. Res. Technol., 45, 603 (2010).
21. G.G.Muley, M.N.Rode, B.H.Pawar, Acta Phys. Pol.A, 116, 1033 (2009).

22. D.Xu, D.Xue, J.Cryst.Growth, 286, 108 (2006).

23. M.O'Keeffe, C.T.Perrino, J.Phys.Chem.Solids, 28, 211 (1967).

24. L.B.Harris, G.J.Vella, J.Chem.Phys., 10, 4294 (1967).

25. L.B.Harris, G.J.Vella, J.Chem.Phys., 58, 4550 (1973).

26. E.D.Yakushkin, E.P.Efremova, A.I.Baranov, Cryst. Rep., 46, 830 (2001).

27 A.N.Levchenko, I.M.Pritula, A.V.Kosinova et al., Proc. of 8th Int. Conf. Laser and FiberOpt. Networks Modeling. (LFNM`2010), 136 (2010).

28. B.V.R.Chowdari, Y.R.Sekhar, Phys.Stat.Sol. (a), 54, 413 (1979).

29. S.Goma, C.M.Padma, C.K.Mahadevan, Mater. Lett., 60, 3701 (2006).

30. J.J.Kweon, C.E.Lee, S.J.Noh et al., J.Appl. Phys., 111, 016102 (2012).

31. E.Chang, J.J.Kweon, J.K.Park et al., Curr. Appl.Phys., 14805 (2014).

32. A.V.Uklein, A.S.Popov, V.V.Multian et al., Nanoscale Res. Lett., 10, 102 (2015).

33. V.Ya.Gayvoronsky，M.A.Kopylovsky，M.S.Brodyn et al., Laser Phys.Lett., 10, 035401 (2013).

34. I.Pritula, V.Gayvoronsky, M.Kopylovsky et al., Functional Materials, 15, 420 (2008).

35. I.Pritula, A.Kosinova, M.Kolybayeva et al., Mater. Res. Bull., 43, 2778 (2008). 